\title{
A polysaccharide from the human commensal Bacteroides fragilis protects against CNS demyelinating disease
}

\author{
J Ochoa-Repáraz ${ }^{1}$, DW Mielcarz ${ }^{2}$, Y Wang $^{2}$, S Begum-Haque ${ }^{1}$, S Dasgupta ${ }^{3}$, DL Kasper $^{3}$ and LH Kasper $^{1}$
}

The intestinal microbiome may have a critical roll in susceptibility or resistance to immune-mediated diseases. Alterations of the gut microflora after oral antibiotic treatment can regulate encephalomyelitis (EAE), an animal model for human multiple sclerosis (MS). We now show that a zwitterionic capsular polysaccharide A (PSA) of Bacteroides fragilis can protect against central nervous system demyelinating disease. Oral administration with purified PSA protected mice against EAE prophylactic and therapeutically. PSA treatment enhanced CD103 expressing dendritic cells (DCs) that accumulated in the cervical lymph nodes. Exposure of naïve DCs to PSA induced the conversion of naïve CD4 ${ }^{+}$T cells into interleukin (IL)-10-producing FoxP3 ${ }^{+}$Treg cells. Protection against EAE was completely abrogated in IL-10-deficient mice. Our results show an important role for a molecule from human commensal bacteria in protecting against EAE and suggest the possibility for protection in MS.

\section{INTRODUCTION}

The mammalian mucosal gastrointestinal tract is a complex ecological environment that contains a heterogeneous population of $>10^{14}$ microorganisms that belong to $\sim 1,000$ different species. ${ }^{1-3}$ These diverse populations are principally composed of anaerobic bacteria, among which the gram-negative Bacteroides species comprise $\sim 25 \%$ of the microflora population. Bacteroides are transferred from mother to infant during the birthing process and can be detected in the gastrointestinal tract of the neonate after approximately 10 days. ${ }^{4}$ As part of the human commensal population, Bacteroides fragilis is symbiotic with the host but if it reaches sterile extraluminal sites can be responsible for tissue infection, bacteremia, abscess formation in the peritoneal cavity, brain, liver, pelvis, or lungs. 5,6

The control of pathogens by the inflammatory process is required to maintain a normal physiologic state that in turn must be regulated to prevent the loss of immune homeostasis. Studies in germ-free animals, born and raised in sterile conditions, have shown that early exposure to both pathogens and non-pathogenic microbes is necessary for the complete development of the gut-associated lymphoid tissues (GALT) and balanced immune development. ${ }^{7}$ Germ-free studies have shown that monocolonization with B. fragilis is sufficient to stimulate early development of the GALT, and to induce normal organogenesis in the spleen and thymus. B. fragilis is sufficient to restore the $\mathrm{T}_{\mathrm{H}}$ 1-immune balance from the otherwise default $\mathrm{T}_{\mathrm{H}}$ 2immune bias of germ-free animals. ${ }^{6-8}$ Interestingly, oral treatment with polysaccharide A (PSA) produced by $B$. fragilis protects against intestinal inflammation by the induction of interleukin (IL)-10-producing regulatory $\mathrm{CD} 4^{+} \mathrm{T}$ cells..$^{9}$ Other zwitterionic polysaccharides, such as the type 1 capsule of Streptococcus pneumoniae also have the ability to modify inflammatory responses in animal models by the induction of interleukin (IL)-10-producing $\mathrm{CD}^{+}{ }^{+} \mathrm{T}_{\text {cells. }}{ }^{10}$

Bacteroides has been associated with the "hygiene hypothesis" in the control of immune homeostasis, ${ }^{11}$ which states that increased vaccination practices, extended usage of antibiotics, and clean environment may alter the colonization of intestinal pathogenic microorganisms such as helminthes and bacterial populations. This could lead to an imbalance between inflammatory $\mathrm{T}_{\mathrm{H}} 1$ and $\mathrm{T}_{\mathrm{H}} 17$, and anti-inflammatory $\mathrm{T}_{\mathrm{H}} 2$ and regulatory cell populations, which has been associated with autoimmune conditions such as allergy and asthma. ${ }^{12}$ We recently showed that reduction of the bacterial content of the gut alters the clinical 
outcome of experimental autoimmune encephalomyelitis (EAE) in mice, the most widely used animal model for multiple sclerosis (MS). ${ }^{13}$ Oral treatment of mice with antibiotics reduced the EAE severity by diminished pro-inflammatory responses and enhanced FoxP $3^{+} \mathrm{T}_{\text {reg }}$ cells that accumulated in mesenteric and cervical lymph nodes (LNs).

In this study, we show that oral treatment with purified PSA conferred protection in SJL/J and C57BL/6 mice. This protection was completely abrogated in IL-10-deficient mice. Our results suggest a potent regulatory role for this specific human commensal bacterial antigen in the control of central nervous system (CNS) demyelination in this experimental model of human MS.

\section{RESULTS}

\section{Oral treatment with purified PSA from $B$. fragilis protects against EAE}

To evaluate the ability of purified PSA to protect against disease, we treated intact, naïve SJL/J (Figure 1a) and C57BL/6 (Figure 1b) mice with $100 \mu \mathrm{g}$ of PSA orally every 3 days starting 6 days before EAE induction, as previously described for experimental colitis. ${ }^{9}$ Treatment with purified PSA delayed the EAE clinical outcome, reduced the severity, and the cumulative scores (Figures $\mathbf{1} \mathbf{c}$ and $\mathbf{d}$ ) of the disease in both strains of mice ( $P=0.0002$ in $\mathrm{SJL} / \mathrm{J}$, and $P=0.004$ in $\mathrm{C} 57 \mathrm{BL} / 6$, by Mann-Whitney $U$-test) when compared with untreated (phosphate-buffered saline (PBS) group) mice. Transversal sections of spinal cords of mice treated with either PSA or PBS showed reduced demyelination and nucleated cell infiltration in mice treated with purified PSA when compared with PBS-treated mice (Figure 1e), in concordance to the reduced severity of the disease.

We next compared the expression of Th1/Th17 transcription factors and cytokines in brains of C57BL/6 mice after PSA treatment to that of untreated mice (Figure 2a). Expression of ROR $\gamma \mathrm{t}$ as well as IL-17 was reduced significantly in EAE mice treated with PSA when compared with PBS-treated mice. Equivalent reductions were observed in the levels of T-bet and interferon (IFN) $-\gamma$, suggesting that both Th17 and Th1 responses were diminished in the brains of mice protected against EAE on oral treatment with PSA. By contrast, brains of PSA-treated mice showed enhanced levels of smad3 expression (that signals transforming growth factor (TGF)- $\beta$ production) when compared with PBS-treated mice. No level of IL-10 expression was found in brains of either PBS- or PSA-treated mice (not shown). No detectable levels of expression of measured transcription factors and cytokines were found in the brains of untreated naive and naïve mice immunized orally with PSA.

Cervical LN leukocytes were cultured for $48 \mathrm{~h}$ in the presence of myelin oligodendrocyte glycoprotein (MOG) $35-55$, used to induce EAE, or media (control) (Figure 2b). IL-17 and IFN- $\gamma$ released to the culture media of cells stimulated with $\mathrm{MOG}_{35-55}$ were significantly reduced in EAE mice treated with PSA when compared with untreated mice, whereas IL-10 production was enhanced significantly. Antigen nonspecific stimulation with anti-CD3 and anti-CD28 antibodies resulted in a similar pattern of cytokine secretion with reduction of both IL-17 and IFN- $\gamma$ in PSA-treated mice (not shown).

\section{Therapeutic treatment with PSA protects EAE}

Therapeutic treatment with purified PSA reduced the severity of EAE severity and cumulative scores of C57BL/ 6 mice when the administration started 3 or 7 days after EAE induction (Figure 3a). A significant reduction in the cumulative scores and EAE intensity in mice treated with PSA on days $3(P=0.004$, Mann-Whitney $U$-test $)$ and $7(P=0.02)$ after EAE induction was observed when compared with PBS-treated mice or those treated $10(P=0.04)$ and 16 days $(P=0.007)$ after EAE induction. The cumulative scores of mice treated on day 10 were also reduced significantly when compared with control PBS-treated mice (Figure 3b). The initiation of the treatment 16 days after the induction of the disease did not confer any protection against clinical disease.

\section{$\mathrm{CD} 103^{+}$dendritic cells (DCs) enhance FoxP3 ${ }^{+}$Treg cell induction in the presence of PSA}

The role of $\mathrm{CD} 11 \mathrm{c}^{\text {high }} \mathrm{CD} 103^{+}$DCs in the conversion of naïve $\mathrm{CD} 4^{+} \mathrm{T}$ cells into Foxp $3^{+}$Treg cells has been shown, ${ }^{14}$ and potential role for commensal bacteria in this conversion suggested. ${ }^{14,15} \mathrm{CD} 11 \mathrm{c}^{\text {high }} \mathrm{CD} 103^{+}$DCs have been found in the GALT and mucosal respiratory tissues. ${ }^{16-18}$ Flow cytometry of the cervical LN of EAE mice treated with PSA showed significant increases in the levels of CD11 $c^{\text {high }} \mathrm{CD} 103^{+}$and $\mathrm{CD} 103^{-}$ DCs when compared with PBS-untreated mice (Figure 4a). Interestingly, the accumulation of $\mathrm{CD} 11 \mathrm{c}^{\text {high }} \mathrm{CD} 103^{+} \mathrm{DCs}$ was only found in the cervical LN of mice treated with PSA that were EAE induced, and not in unchallenged mice and subsequently treated with PSA or in mice treated with PSA and exposed to pertussis toxin and complete Freund's adjuvant, the adjuvants used to induce EAE. These results suggest that an inflammatory stimulus of the CNS is necessary for the accumulation of $\mathrm{CD} 11 \mathrm{c}^{\text {high }} \mathrm{CD} 103^{+}$DCs in the cervical LN. We further characterized the $\mathrm{CD}_{103}{ }^{+}$and $\mathrm{CD} 103^{-}$sub-populations of $\mathrm{CD} 11 \mathrm{c}^{\text {high }}$ DCs found in the cervical LN of EAE mice treated with PSA and PBS (untreated) (Figure $4 \mathbf{b}$ ). Similar profiles were found in the DC sub-populations of PBS- and PSA-treated mice: $\mathrm{CD} 103^{+} \mathrm{CD} 11 \mathrm{c}^{\text {high }}$ DCs expressed enhanced levels of CD11b and TLR2 when compared with CD103- DCs. Major histocompatibility complex class II, and CD86 activation markers were also increased in the $\mathrm{CD}_{103}{ }^{+}$sub-population. By contrast, the expression of $\mathrm{B} 220$ was reduced in $\mathrm{CD} 103^{+}$when compared with $\mathrm{CD}_{103^{-}}$DCs. No expression of CD80 was found in either $\mathrm{CD}_{103^{-}}$or $\mathrm{CD} 103^{+}$DCs.

We analyzed the role of PSA in the acquisition of regulatory phenotypes by naïve $\mathrm{CD} 4^{+} \mathrm{T}$ cells when exposed to $\mathrm{CD} 103^{+1}$ ${ }^{-} \mathrm{CD} 11 c^{\text {high }}$ DCs. CD $103^{+/-}$CD $11 c^{\text {high }}$ DCs were sorted from the LNs and co-cultured with naïve splenic $\mathrm{FoxP}^{-}{ }^{-} \mathrm{CD} 4^{+} \mathrm{T}$ cells in the presence of PBS, purified PSA $\left(100 \mu \mathrm{g} \mathrm{ml}^{-1}\right)$ or $4 \mathrm{nM}$ retinoic acid (RA) and $5 \mathrm{ng} \mathrm{m}^{-1}$ of TGF- $\beta$ (Figure 5a). Exposure of $\mathrm{CD}_{103^{+}} \mathrm{DCs}$ from naive mice to purified PSA enhanced significantly the conversion of FoxP $3-\mathrm{CD}^{+}{ }^{+} \mathrm{T}$ cells into $\mathrm{CD} 4{ }^{+} \mathrm{FoxP} 3^{+}$ cell when compared with PBS alone $(P=0.01)$, however, the 

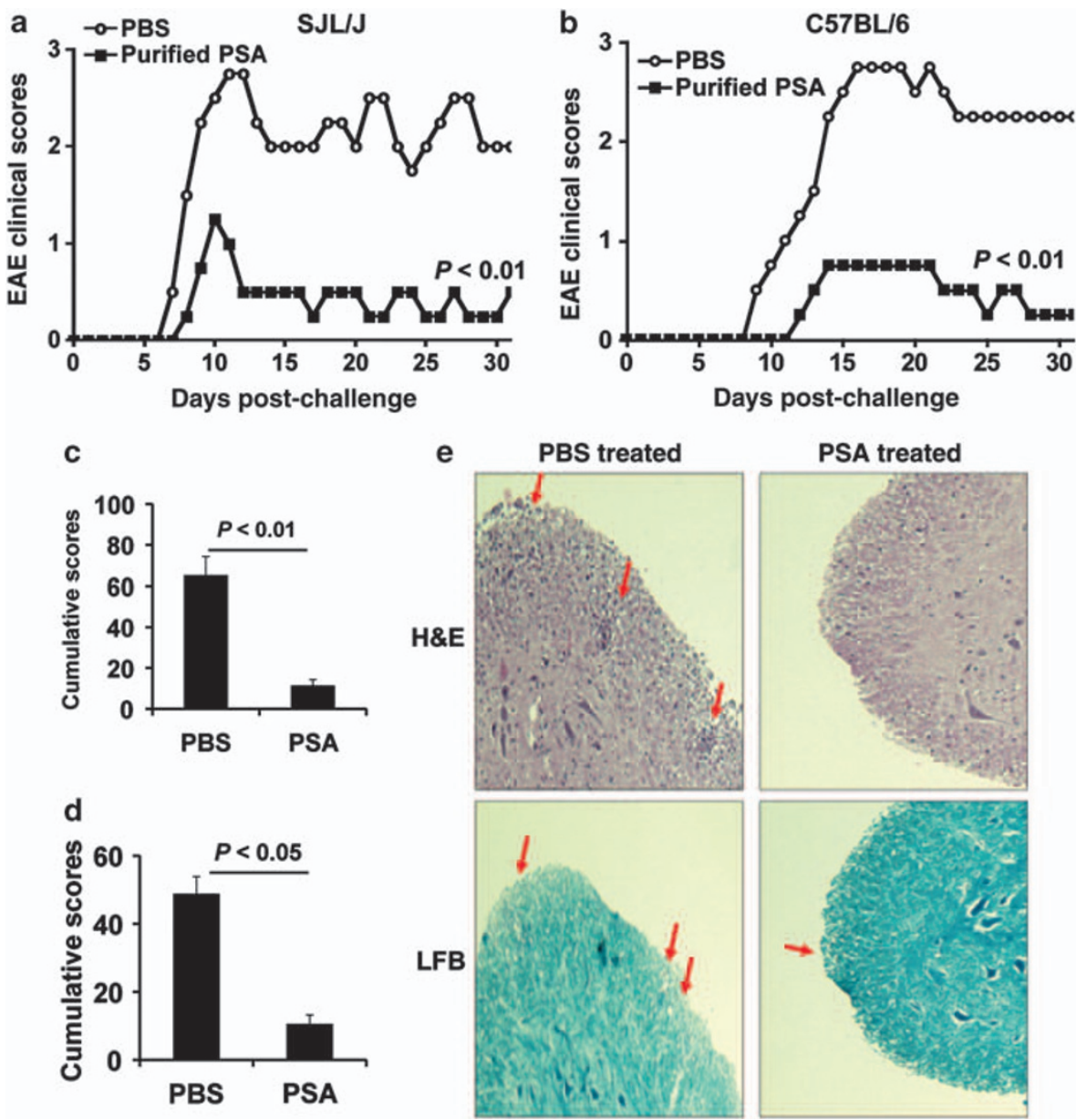

Figure 1 Oral prophylactic treatment with purified PSA protects mice against EAE. SJL (a) and C57BL/6 (b) mice were immunized with $100 \mu \mathrm{g}$ of purified PSA by oral gavages every 3 days. Prophylactic treatment was initiated 6 days before EAE induction (with PLP $P_{139-151}$ for SJL/J and MOG $35-55$ for C57BL/6 mice) and terminated 9 days after disease induction. Depicted are the combined results of three independent experiments ( $n=12$, per group). $P<0.01$ (Mann-Whitney $U$-test). Oral prophylactic treatment with purified PSA reduced EAE cumulative scores in SJL/J (c) and C57BL/6 mice (d) when compared with PBS-treated mice. Cumulative scores were calculated as the sum of all EAE clinical scores divided by the number of mice per group. Graphs represent the combination of all independent experiments. Oral treatment of C57BL/6 mice with purified PSA reduced nucleated cell infiltration into the CNS and demyelination (e). On day 19 after the disease induction, transversal sections of spinal cords were harvested and fixed in $10 \%$ formalin. Sections were stained with either hematoxylin and eosin (H\&E) (infiltration of nucleated cells) or luxol fast blue (demyelination).

conversion rates were significantly lower $(P=0.002)$ than those observed in the positive controls for conversion (RA and TGF- $\beta$ ). When $\mathrm{CD} 4^{+} \mathrm{T}$ cells were cultured with $\mathrm{CD} 103^{-}$and PSA, the conversion of FoxP3 ${ }^{-} \mathrm{CD}^{+}{ }^{+} \mathrm{T}$ cells into FoxP3 ${ }^{+}$Treg cells was not observed. Cytokine production in cells co-cultured with PSA was compared. No production of IL-17 was found in cells exposed to PSA, whereas TGF- $\beta$ and in particular IL-10 were enhanced significantly, as well as IFN- $\gamma$ (not significant), in co-cultures that induced the conversion of FoxP $3^{+}$Treg cells (Figure 5b) on restimulation with PSA and RA/TGF- $\beta$. The levels of IL-10 and TGF- $\beta$ were enhanced significantly when cells were stimulated with RA/TGF- $\beta$ when compared with PSA stimulation, as observed in the conversion rates shown (Figure 5a). IL-10 expression was compared in the FoxP3 ${ }^{+}$subpopulation of $\mathrm{T}$ cells on culture with DCs exposed to purified PSA and RA/TGF- $\beta$ (Figure 5c). A significant increase in IL-10 expression was found in FoxP3 ${ }^{+}$Treg cells converted after culture with $\mathrm{CD} 103^{+}$DCs and purified PSA when compared with PBS stimulation $(P<0.05)$. Culture of CD103 ${ }^{+}$DCs with RA/TGF- $\beta$ also enhanced the frequency of IL- $10^{+}$FoxP ${ }^{+}$Treg cells when compared with PBS $(P<0.05)$. No significant enhancements of IL-10 levels were measured on culture of $\mathrm{CD} 4^{+} \mathrm{T}$ cells with CD103- DCs (not shown).

The frequencies of $\mathrm{FoxP}^{+}$Treg cells were compared in the cervical $\mathrm{LN}$ of EAE mice (Figure 5d). As occurred with $\mathrm{CD} 103^{+} \mathrm{DCs}$, FoxP3 ${ }^{+}$Treg cell frequencies were significantly enhanced in the cervical LN of EAE mice treated with PSA when compared with PBS-treated mice $(P<0.05)$. In spite of the differences in the frequency of FoxP $3^{+}$Treg cells, no significant increases were observed in the numbers (not show). The cervical LN of mice not subjected to EAE induction showed no enhancement of FoxP3 ${ }^{+}$Treg cells on immunization with PBS or purified PSA.

\section{PSA protection against EAE is IL-10 dependent}

As IL-10 seemed to be enhanced in FoxP ${ }^{+}$Treg cells converted on PSA exposure, we next compared the production 

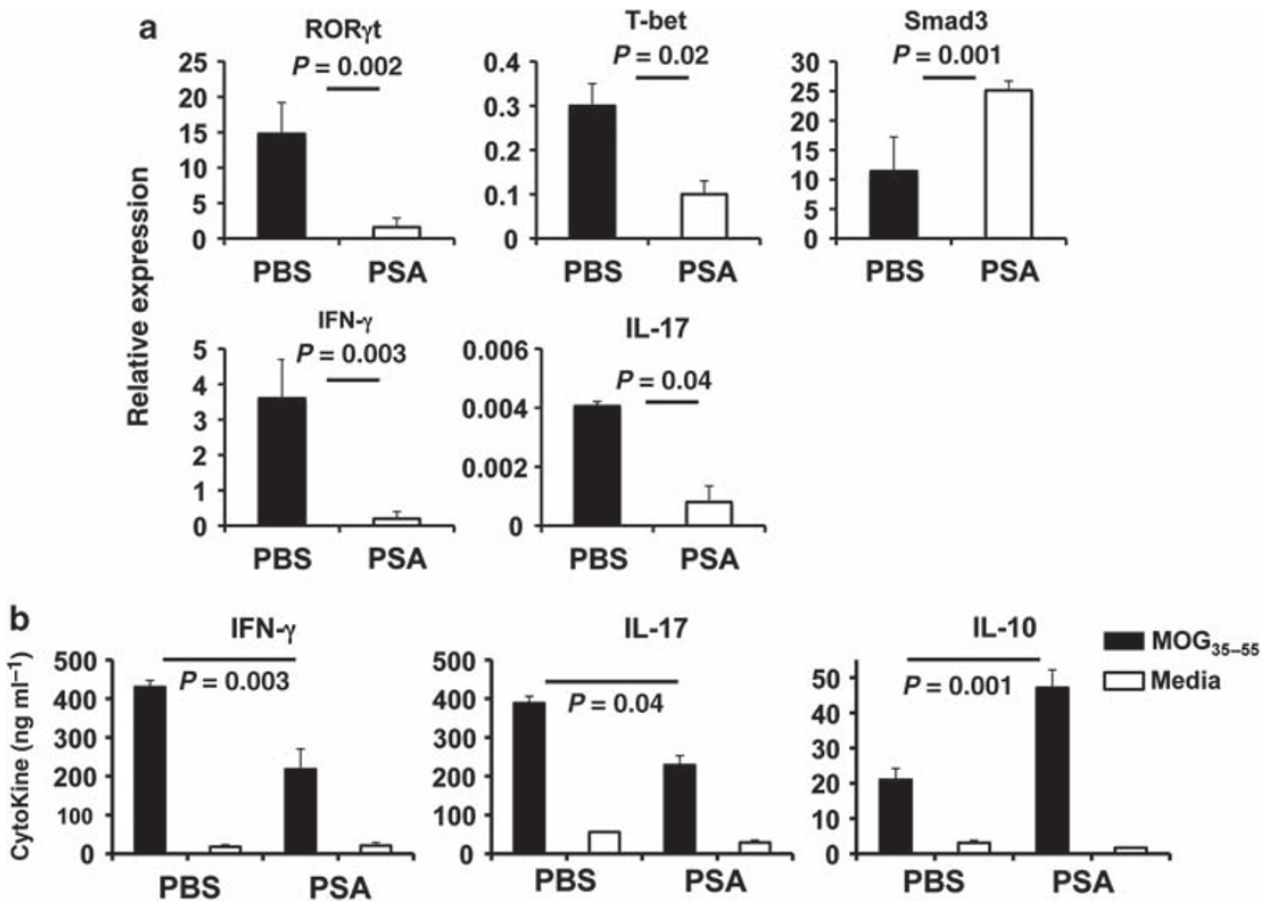

Figure 2 Prophylactic treatment of EAE mice with PSA reduces Th17 and Th1 responses. Brains of mice were harvested in the peak of the disease (day 19) and relative expression of IFN- $\gamma$, IL-17, IL-10 cytokines as well as ROR $\gamma$ t, T-bet, and Smad3 transcription factors were measured by PCR (relative expression is shown as $\Delta \Delta \mathrm{Ct}$ after normalized with naïve levels) (a). Total leukocytes harvested from cervical LN of PBS- and PSA-treated mice were cultured for $48 \mathrm{~h}$ in the presence of $\mathrm{MOG}_{35-55}$ and media (b). IFN- $\gamma$ and IL-17 levels were reduced significantly in leukocytes from PSAtreated mice when compared with PBS-treated mice. By contrast, IL-10 production was significantly enhanced in mice treated with purified PSA. Depicted are the means \pm s.d. from three separate experiments ( $n=6$ per group).

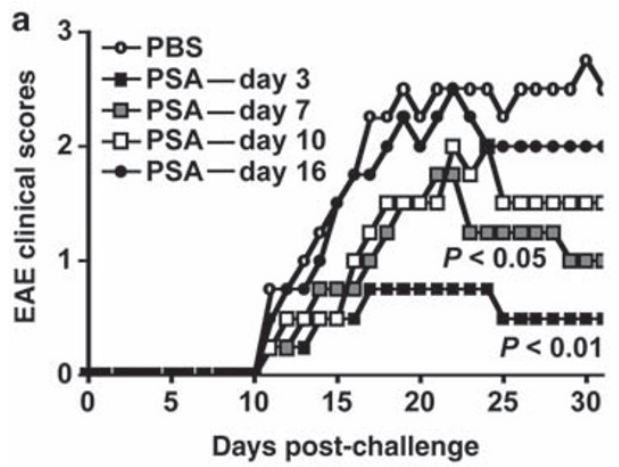

b

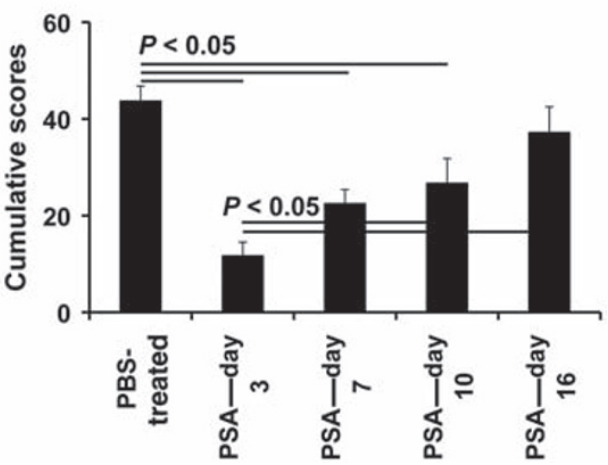

Figure 3 Oral therapeutic treatment with purified PSA protects mice against EAE. C57BL/6 mice were treated with $100 \mu \mathrm{g}$ of purified PSA by oral gavages every 3 days, starting at days 3, 7, 10, or 16 after EAE induction (a). Depicted are the combined results of two independent experiments ( $n=8$, per group). $P<0.01$ (Mann-Whitney $U$-test). Therapeutic treatment with PSA 3, 7, and 10 days after EAE induction reduced cumulative scores when compared with PBS-treated mice (b). Treatment of mice with purified PSA 16 days after EAE induction had no effect in the cumulative scores when compared with untreated mice. Cumulative scores were calculated as the sum of all EAE clinical scores divided by the number of mice per group. Graphs represent the combination of all independent experiments.

of IL-10 in leukocytes obtained from the cervical LN of naive C57BL/6 mice exposed to PSA and $\mathrm{MOG}_{35-55}$. Cells were cultured in vitro with purified PSA, $\mathrm{MOG}_{35-55}$, or combined PSA and $\mathrm{MOG}_{35-55}$. Purified PSA induced the production of IL-10 in naïve cells (Figure 6a). IL-10 production was increased in cells stimulated with increasing concentrations of PSA. Stimulation with $\mathrm{MOG}_{35-55}$ did not enhance the IL-10 produced by naïve cells, whereas culture with PSA and
MOG reduced IL-10 production when compared with PSA only stimulation.

The importance of IL-10 in the protection conferred by oral administration of purified PSA was evaluated. IL-10-deficient and wild-type C57BL/ 6 mice were treated with $100 \mu \mathrm{g}$ of PSA or PBS orally every 3 days starting 6 days before EAE induction. Induction of EAE in IL-10 knockout mice resulted in clinical disease similar to that observed in wild-type C57BL/6 mice 
a

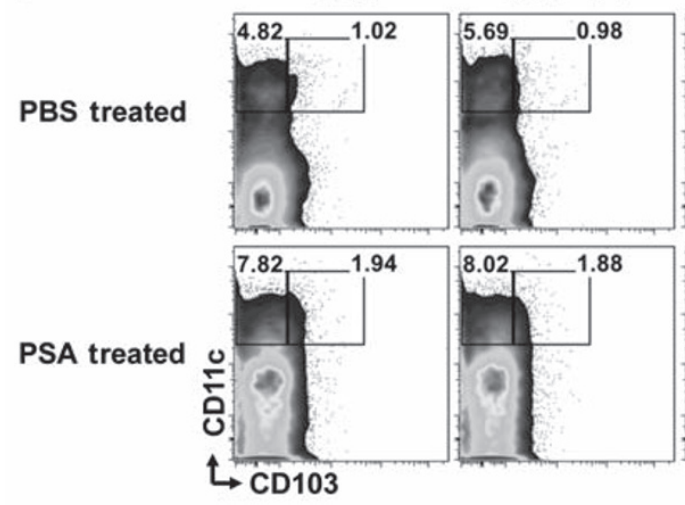

EAE
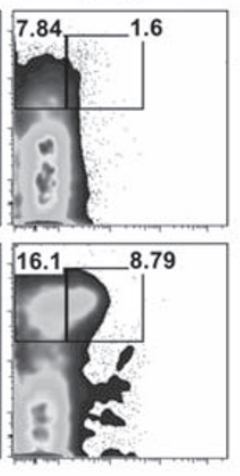
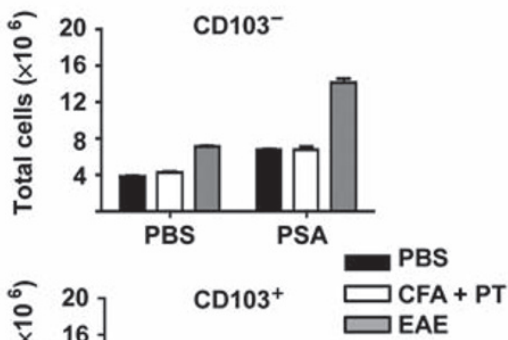

을 16 -

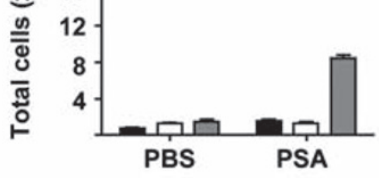

b PBS treated $\mathrm{CD}^{-\mathrm{DC}}{ }^{-} \mathrm{DS}$

CD103+ DCs

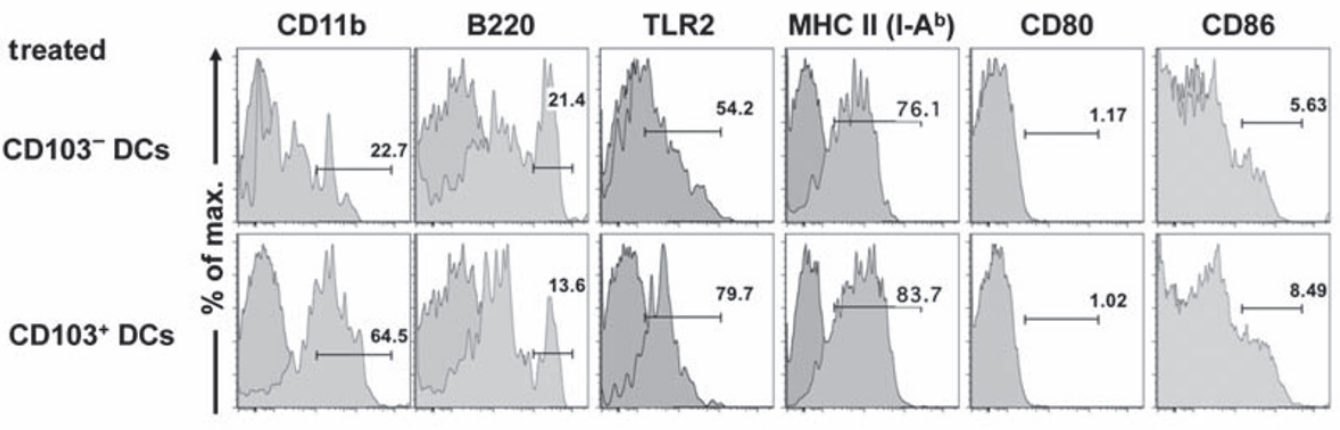
TLR2

MHC II (I-A b) CD80 CD86

PSA treated

CD103- DCs
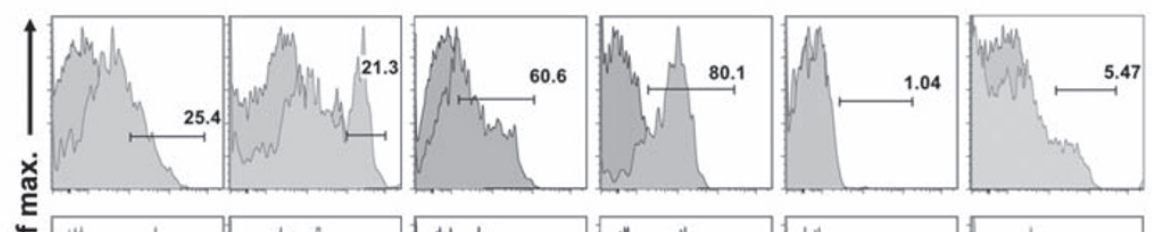

CD103+ DCs
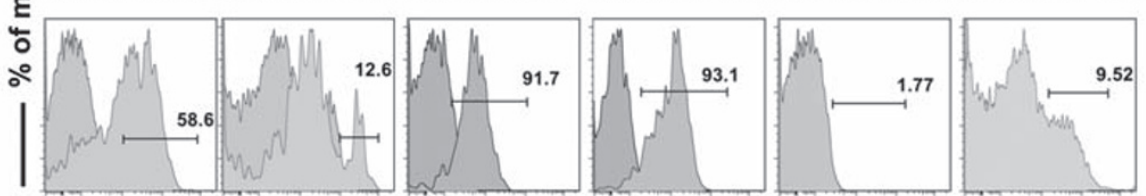

Figure 4 PSA treatment of EAE mice enhances the percentages of CD103 ${ }^{+}$and $C D 103^{-}$DCs in the cervical LN. Mice were killed 15 days after EAE induction. Flow cytometry analysis revealed significant accumulations of CD11 ${ }^{\text {high }} \mathrm{CD}_{103^{+/-}} \mathrm{DC}$ s in cervical LN of PSA-treated mice when compared with untreated EAE mice. Of particular interest was the observation that oral treatment of naïve non-EAE mice with purified PSA did not increase the percentages of CD103+ DCs in the cervical LNs. Injections with the adjuvants used to induce EAE (compete Freund's adjuvant and Pertussis toxin) did not have an effect in such accumulation (a). These results suggest that exposure to EAE antigens may be critical in the trafficking and migration of the $\mathrm{CD}_{103^{+}} \mathrm{DC}$ to the CNS and its closely associated lymphoid tissue. CD103+ DCs accumulated in the cervical LN of EAE mice were further characterized (b). Depicted are the representative results of an experiment from three separate experiments, and the combined results (mean \pm s.d.) for all groups ( $n=6$, per group).

in onset, severity, and cumulative scores (Figures $\mathbf{6 b}$ and $\mathbf{c}$ ). The protection against EAE by PSA in parental wild-type C57Bl/6 mice was completely abrogated in C57Bl/6 IL-10deficient mice.

\section{DISCUSSION}

Alterations of the gut commensal bacteria populations by oral treatment with antibiotics can influence the development of EAE. ${ }^{13,19}$ We herein show that oral treatment with a single purified polysaccharide antigen derived from $B$. fragilis, a non-toxic component of the normal human commensal microbiota protects mice against a CNS demyelinating disease. Moreover, we show that EAE protection with PSA is associated with a significant accumulation of $\mathrm{CD} 103^{+}$DCs and FoxP3 ${ }^{+} \mathrm{T}$ regulatory cells in the cervical LN. The CD103 ${ }^{+}$ DCs induce the conversion of naïve $\mathrm{CD} 4^{+} \mathrm{T}$ cells into IL-10producing FoxP3 ${ }^{+}$Treg cells that confer protection against disease when adoptively transferred (not shown). The mechanism of protection by PSA-induced IL-10-producing Treg cells is currently being evaluated. A recent report has shown that the administration of a mixture of commensal microorganims of the gut can protect against experimental EAE. ${ }^{20}$ The protection observed was also IL-10 dependent. Our findings have identified the capacity of a single polysaccharide that induces similar level of protection in two genetically diverse strains of mice suggesting a broad genetic basis for conferring 

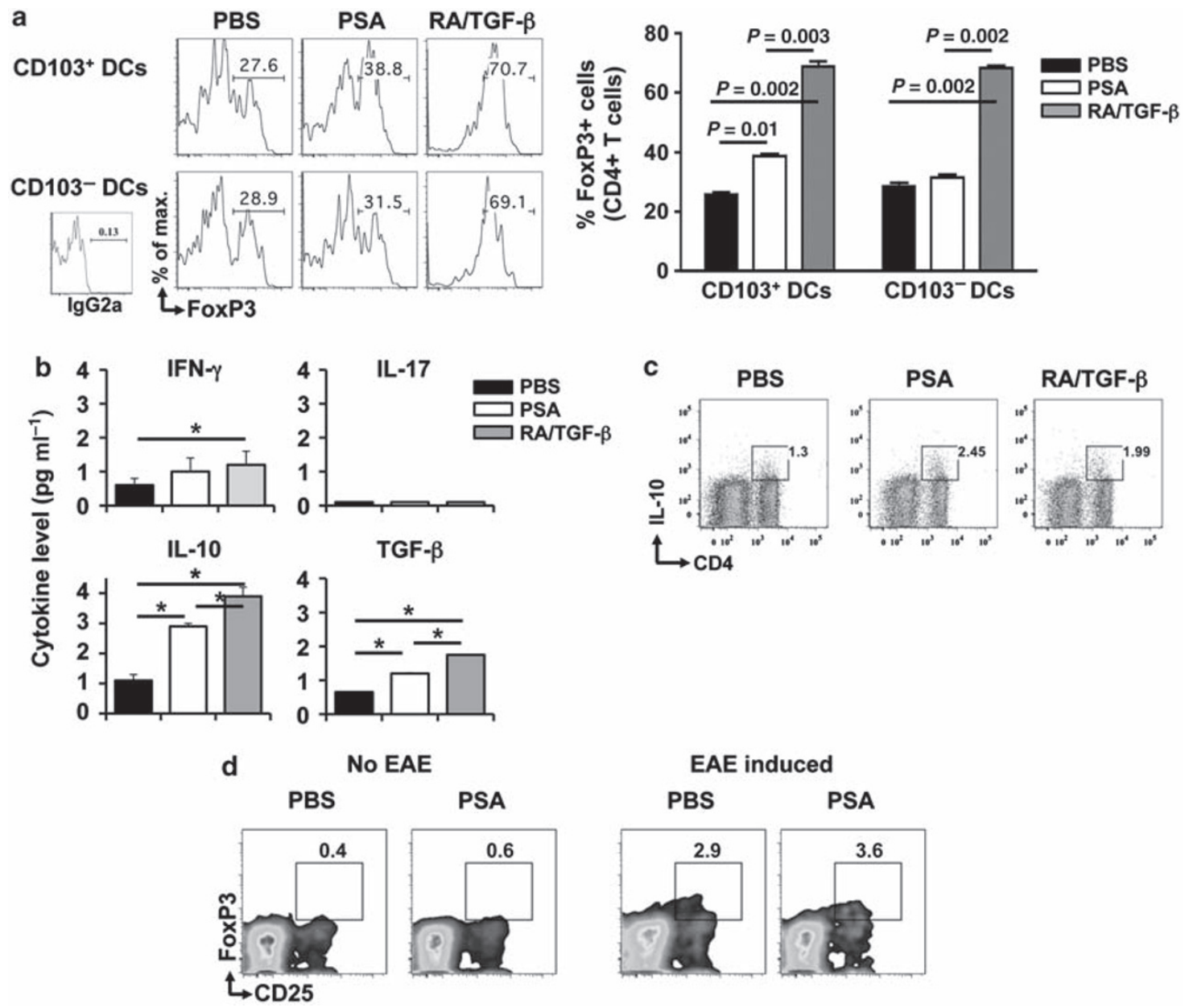

Figure 5 Exposure of $\mathrm{CD}_{103^{+}} \mathrm{DC}$ s to purified PSA enhances IL-10-producing FoxP3 ${ }^{+}$Treg cell conversion in vitro. DCs were harvested from cervical LN of naïve C57BL/6 mice and sorted into CD103 ${ }^{+/-}$CD11 $\mathrm{C}^{+} \mathrm{DCs}$. Cells were co-cultured with CD4 ${ }^{+} \mathrm{CD} 25^{-} \mathrm{T}$ cells sorted from spleens of naïve mice in the presence of PBS, purified PSA $\left(100 \mu \mathrm{g} \mathrm{ml}^{-1}\right)$ or RA $(4 \mathrm{nM})$ and TGF- $\beta\left(5 \mathrm{ng} \mathrm{ml}^{-1}\right)(\mathbf{a})$. FoxP3 acquisition by CD4 ${ }^{+} \mathrm{T}_{\text {cells }}$ was measured by flow cytometry. Depicted are the representative results of an experiment from three separate experiments, and the combined results (mean \pm s.d.) for all groups ( $n=6$, per group). IFN- $\gamma$, IL-17, IL-10, and TGF- $\beta$ cytokines were measured by specific enzyme-linked immunosorbent assay (ELISA) in the supernatants of FoxP3 ${ }^{+}$-converted cells $\left(n=6\right.$, per group). ${ }^{\star} P<0.05$, by $t$-test (b). Flow cytometry was used to compare the frequencies of IL- $10^{+}$cells in FoxP $3^{+} \mathrm{CD} 25^{+} \mathrm{CD} 4^{+} \mathrm{T}$ cells after the conversion studies with $\mathrm{CD} 103^{+} \mathrm{DC}$ s exposed to with purified PSA (c). Flow cytometry was used to compare the frequencies of FoxP $3^{+} \mathrm{CD} 25^{+} \mathrm{CD} 4^{+} \mathrm{T}$ cells gated in cervical $\mathrm{LN}$ in mice treated orally with PSA and PBS (d). Depicted are the combined results (mean \pm s.d.) from two separate experiments ( $n=8$, per group).

protection by these ubiquitous human and mammalian commensal bacteria.

Previous studies have shown that $\mathrm{CD} 4{ }^{+} \mathrm{T}$-cell activation by PSA is dependent on the presentation of the antigen by CD11 $\mathrm{c}^{+}$ DCs. ${ }^{21}$ After oral treatment of mice with fluorescence-labeled PSA, the polysaccharide is associated with CD $11 \mathrm{c}^{+}$DCs in the mesenteric LN, suggesting that DCs sample PSA from the intestine and migrate to the mesenteric lymph node to initiate an immune response. Our observations suggest that $\mathrm{CD} 103^{+}$ DCs are involved in the regulation shown by exposure to PSA. Exposure to purified PSA enhanced the capacity of naïve $\mathrm{CD}_{103}{ }^{+} \mathrm{DCs}$ to convert CD4 ${ }^{+} \mathrm{T}$ cells in vitro into FoxP3 ${ }^{+}$Treg cells. Interestingly, oral treatment of EAE mice with purified PSA induced the accumulation of $\mathrm{CD} 103^{+}$DCs in the cervical LN, whereas we observed no accumulation in naïve mice subjected to immunization with PSA. CD103- DCs were also enhanced in EAE mice treated with PSA; however, they expressed reduced levels of activation markers and did not enhance Treg cell conversion in vitro. This is the first report to show an accumulation of $\mathrm{CD}_{103}{ }^{+}$DCs in other lymphoid tissues outside the GALT and respiratory mucosal tissues. ${ }^{16-18}$ It is relevant to note that the accumulation observed required an inflammatory process of the CNS. We are currently examining the mechanisms by which these mucosal DCs could migrate and/or accumulate in the cervical LN and the CNS.

Oral treatment with purified PSA induced a significant reduction of the Th1 and Th17 responses, measured in the brains and cervical LN of EAE mice. Enhanced levels of IL-10 secretion and expression were associated with oral administration of PSA. Studies by one of us (Dennis L Kasper, Harvard Medical school) have shown that PSA can influence the production of IL-10 and IFN- $\gamma$ in $\mathrm{CD}^{+} \mathrm{T}$ cells and control $\mathrm{T}_{\mathrm{H}} 1 / \mathrm{T}_{\mathrm{H}} 2$ balance in germfree animals. ${ }^{8,9} \mathrm{IL}-10$-producing $\mathrm{CD} 4{ }^{+} \mathrm{CD} 45 \mathrm{rb}^{\text {low }} \mathrm{T}$ cells are induced in response to PSA administration and are protective in 

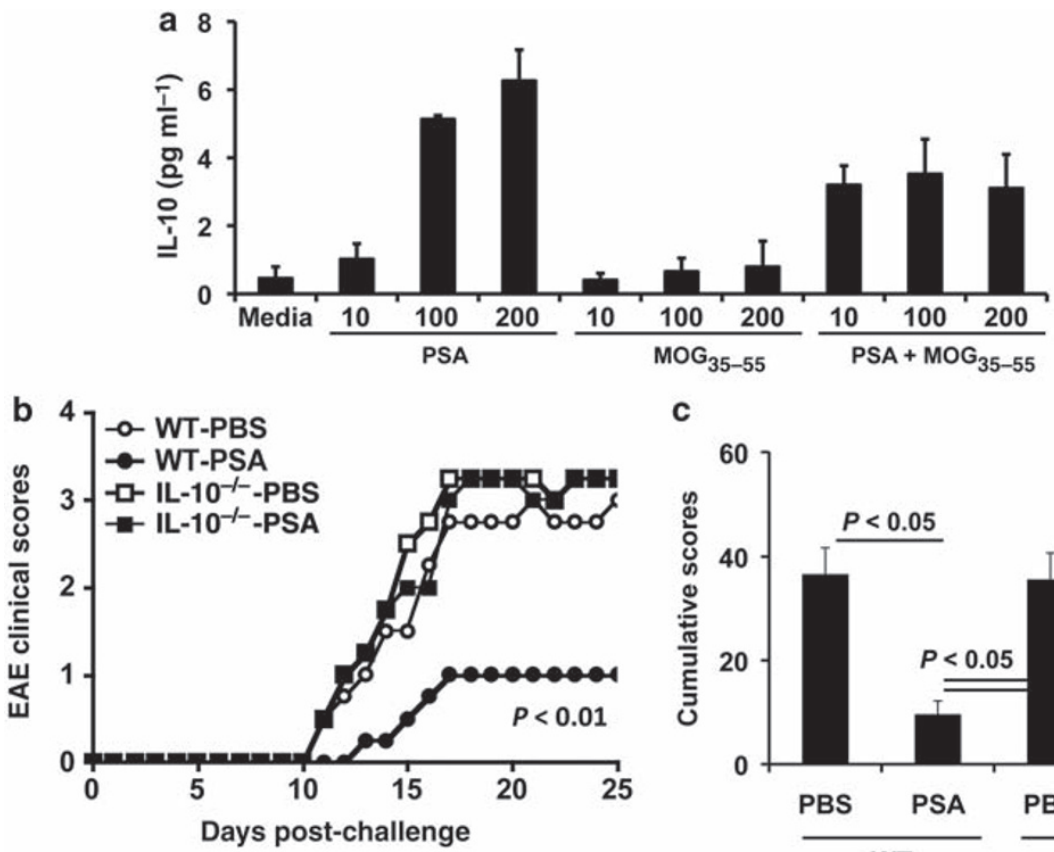

c

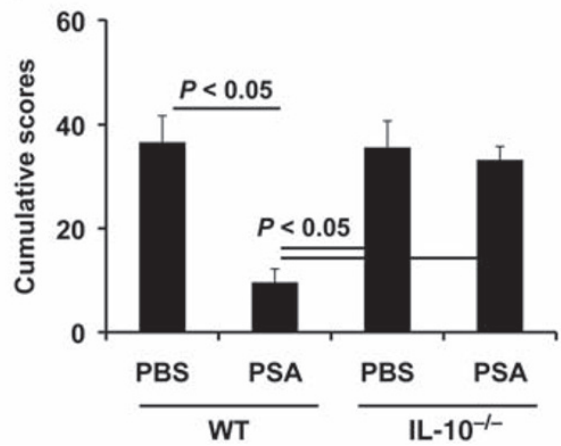

Figure 6 Protection depends on IL-10 production. Total leukocytes were obtained from the cervical LNs of naive C57BL/6 mice and cultured in vitro with purified PSA $\left(10,100\right.$, or $\left.200 \mu \mathrm{g} \mathrm{ml}^{-1}\right), \mathrm{MOG}_{35-55}\left(10,100\right.$, or $\left.200 \mu \mathrm{g} \mathrm{ml}^{-1}\right)$, or combined PSA and MOG $35-55\left(10,100\right.$, or $200 \mu \mathrm{g} \mathrm{ml}{ }^{-1}$ of each) (a). After $48 \mathrm{~h}$ of culture, the supernatants were collected and IL-10 levels compared by specific enzyme-linked immunosorbent assay (ELISA). Purified PSA induced the production of IL-10 in cells. Depicted are the combined results (mean \pm s.d.) from two separate experiments ( $n=6$, per group). Deficiency in IL-10 production abrogated the protection conferred by PSA (b). IL-10 knockout mice and wild-type C57BL/6 mice were treated with $100 \mu \mathrm{g}$ of PSA or PBS orally every 3 days starting 6 days before EAE induction. Depicted are the combined results of two independent experiments ( $n=8$, per group). $P<0.01$ (Mann-Whitney $U$-test). Deficiency in IL-10 production restored the EAE cumulative scores in PSA-treated mice (c). Graphs represent the combination of all independent experiments.

a Helicobacter hepaticus model of experimental colitis. ${ }^{9}$ We now show that PSA can control the development of a CNS demyelinating disease. There are substantial differences in experimental disease model used in the previous reports on PSA and our EAE model, however, the remarkable IL-10 dependence of the protection induced by PSA could suggest that other regulatory $\mathrm{T}$ cells, such as $\operatorname{Tr} 1$ cells, as well as B-cell populations could be involved in the immune regulation induced by the polysaccharide.

Although PSA-converted Treg cells produced a significant level of TGF- $\beta$ compared with naive cells, the TGF- $\beta$ levels were remarkably lower in comparison with IL-10. Both untreated as well as purified PSA-treated IL-10-deficient mice developed a severe form of EAE. Earlier studies have confirmed a critical anti-inflammatory role of IL-10 in the protection to EAE. ${ }^{22-24}$ The reduction of the susceptibility of IL-10 knockout mice to EAE has been shown, confirming the model as a valid mechanism to compare the induction of protective immunity by IL-10-mediated oral tolerance. ${ }^{22}$ In the studies presented, disease in IL-10-deficient mice resulted in EAE that was unresponsive to oral administration of purified PSA. Furthermore, PSA treatment failed to reduce the symptoms of EAE in IL-10-deficient mice when compared with untreated mice. PSA also enhanced the production of IFN- $\gamma$, although the increase measured was not significant when compared with those observed in PBSstimulated cells, and oral treatment with PSA reduced IFN- $\gamma$ levels in brains and LNs. The role of IFN- $\gamma$ in EAE induction and/or protection was controversial until IL-17 was identified as the primary inflammatory mediator responsible for the development of EAE. ${ }^{25-27}$ In vivo neutralization of IFN $-\gamma,{ }^{28,29}$ IFN- $\gamma$-deficient mice, ${ }^{30,31}$ or IFN- $\gamma$ receptor-deficient mice ${ }^{32}$ enhance EAE severity, suggesting that IFN- $\gamma$ is important for protection by possibly dampening IL-17 generation, as recently suggested. ${ }^{33-35}$ In contrast, delayed neutralization of IFN- $\gamma$ after EAE challenge with anti-IFN- $\gamma$ mAbs protected EAE-susceptible animals. ${ }^{36,37}$

In the studies presented, we show the critical role for a single polysaccharide antigen derived from the human and mammalian gut commensal $B$. fragilis in maintaining immune homeostasis distal to the GALT. Oral administration with PSA purified from wild-type $B$. fragilis induced prophylactic and therapeutic protection against the development of EAE in an IL-10-dependent mechanism. The clinical implications of our observations support an important and novel role for commensal bacterial antigen(s) in regulating peripheral immune homeostasis. Protection against CNS disease by this bacterial antigen seems to be associated with the trafficking and migration of a population of gut-derived $\mathrm{CD} 103^{+} \mathrm{DCs}$ to CNS-associated lymphoid tissue, a never previously reported occurrence suggesting an important biologic interaction between the gut mucosal tissue and the brain and spinal cord. Accordingly, adjustment to the gut microbiota may be a reasonable pathway by which to control disease pathogenesis and offer an important pathway for the treatment of MS and perhaps other autoimmune conditions. 


\section{METHODS}

Mice and treatments. Female 6 weeks old SJL/J and C57BL/6 and IL-10 ${ }^{-1-}$ (C57BL/6 background) mice were obtained from the Jackson Laboratories (Bar Harbor, ME). All animal care and procedures were in accordance with at Dartmouth College Animal Resources Center institutional policies for animal health and well-being. Mice were treated orally with $100 \mu \mathrm{g}$ of purified PSA by oral gavages every 3 days. Prophylactic treatment was initiated 6 days before EAE induction and terminated 9 days after disease induction. For therapeutic treatment, C57BL/ 6 mice were given $100 \mu \mathrm{g}$ of purified PSA by oral gavages every 3 days starting at $3,7,10$, or 16 days after EAE induction.

EAE induction. SJL or C57BL/6 mice were challenged subcutaneously with $200 \mu \mathrm{g}$ proteolipid protein (PLP) ${ }_{139-151}$ or $250 \mu \mathrm{g} \mathrm{MOG}_{35-55}$ (Peptides International; Louisville, KY), respectively in $200 \mu$ of Complete Freund's Adjuvant (Sigma, St Louis, MO). On days 0 and 2 after challenge, SJL and C57BL/6 mice received intraperitoneal. 200 or $250 \mathrm{ng}$ of Bordetella pertussis toxin (PT; List Biological Laboratories, Campbell, CA), respectively. ${ }^{38}$ Mice were monitored and scored daily for disease progression. ${ }^{38}$

Cytokine detection by cytokine enzyme-linked immunosorbent assay. Specific cytokine enzyme-linked immunosorbent assay were used to quantify triplicate sets of supernatants. Cells were cultured in 24 -well tissue plates at $2 \times 10^{6} \mathrm{cells} \mathrm{ml}^{-1}$ in the presence of anti-CD3 $\mathrm{mAb}$-coated wells $\left(10 \mu \mathrm{g} \mathrm{ml}^{-1}\right.$; BD Pharmingen, San Diego, CA $)$, plus the soluble anti-CD28 mAb $\left(5.0 \mu \mathrm{g} \mathrm{ml}^{-1}\right.$; BD Pharmingen $)$ for 2 days, $\mathrm{MOG}_{35-55}$ or media. ${ }^{38}$

PCR detection of cytokine mRNA. In all, $1 \mu \mathrm{g}$ of QIAgen RNeasypurified (Qiagen, Germantown, MD) mRNA was reverse transcribed using Multiscribe RT (Amersham Biosciences AB, Uppsala, Sweden). Complementary DNA (200 ng) was amplified using the x2 SYBR green mix (Applied Biosystems, Foster City, CA) on a Bio-Rad iCycler (Hercules, CA). Relative expressions were normalized ( $\beta$-actin sample- $\beta$ actin of naïe samples) and expressed using the cycle threshold method, where relative expression $=2 \wedge(\exp -$ actin $) \times 1,000$.

Fluorescence-activated cell sorting analysis. Single cervical lymph node (CLN) lymphocyte preparations were stained using conventional methods. T-cell subsets were analyzed using fluorochrome-conjugated mAbs (BD Pharmingen) for CD4 and CD25. Intracellular staining for FoxP3 and IL-10 was performed using fluorochrome labeled anti- Foxp3 (clone FJK-16s; eBioscience, San Diego, CA) and IL-10 (BD Pharmingen) mAbs. DCs were analyzed using CD11c, CD11b, CD103, B220, TLR2, I-A ${ }^{b}$ major histocompatibility complex class II, CD80, and CD86 (BD Pharmingen). Bound fluorescence was analyzed with a fluorescence-activated cell sorting Canto (BD Biosciences).

Cell purifications. CD11c ${ }^{+}$cells were enriched with magnetic beads (StemCell Technologies, Vancouver, Canada) and then sorted (FACSVantage with Turbo-Sort, BD Biosciences) after staining with fluorescein isothiocyanate-anti-CD103 into CD $11 \mathrm{c}^{\text {high }} \mathrm{CD} 103^{+/-}$ cells. CD4 ${ }^{+} \mathrm{T}$ cells were obtained with magnetic beads (Dynal Biotech ASA, Oslo, Norway). The enriched CD $4^{+} \mathrm{T}$ cells were cell sorted for $\mathrm{CD} 4{ }^{+} \mathrm{CD} 25^{-} \mathrm{T}$ cells using fluorescein isothiocyanate-anti-CD4 and phycoerythrin-anti-CD25 mAbs (BD Pharmingen).

In vitro conversion assays. To compare the role of CD $11 \mathrm{c}^{\text {high }} \mathrm{CD} 103^{+/-}$ cells in the conversion of $\mathrm{CD} 4{ }^{+} \mathrm{CD} 25^{-} \mathrm{T}$ cells into FoxP $3^{+} \mathrm{T}_{\text {reg }}$ cells, $1 \times 10^{4}$ sorted CD103 $3^{-1+} \mathrm{CD} 11 \mathrm{c}^{\text {high }}$ cells were co-cultured with $5 \times 10^{4}$ splenic naïve $\mathrm{CD} 4{ }^{+} \mathrm{CD} 25^{-} \mathrm{T}$ cells. Cultures were set in the presence of PBS, purified PSA $\left(100 \mu \mathrm{g} \mathrm{ml}^{-1}\right)$ or $4 \mathrm{nM} \mathrm{RA}$ and $5 \mathrm{ng} \mu \mathrm{l}^{-1}$ of TGF- $\beta$. FoxP3 acquisition by $\mathrm{CD} 4{ }^{+} \mathrm{T}$ cells was measured by flow cytometry.
Statistical analysis. The student $t$-test was applied to show differences of combined experiments in cumulative clinical scores, luminex, and enzyme-linked immunosorbent assay detection of cytokines as well as in the flow cytometry of Treg cell and DC experiments. Mann-Whitney $U$-test was applied to show differences in EAE clinical scores. $P$-values $<0.05$ and $<0.01$ are indicated.

\section{ACKNOWLEDGMENTS}

This work was supported by the Dartmouth-Hitchcock Foundation (JO-R; Tiffany Blake Fellowship \# 205-702B), the NCRR COBRE (Pilot Project \# 4 YR06), and training grants from TEVA Neuroscience (LHK; grant \# 50-2033-TEVA Neuroscience Murray B Bornstein Fund) and the National Multiple Sclerosis Society (LHK; grant \# CA1027A1/3). We thank Azizul Haque, Jacqueline Y Channon Smith, Marc Christy, John DeLong, Kathleen Smith and Alan J Bergeron for technical support and critical review of the paper.

\section{DISCLOSURE}

The authors declared no conflict of interest.

() 2010 Society for Mucosal Immunology

\section{REFERENCES}

1. Zoetendal, E.G., Rajilic-Stojanovic, M. \& de Vos, W.M. High-throughput diversity and functionality analysis of the gastrointestinal tract microbiota. Gut 57, 1605-1615 (2008).

2. Booijink, C.C., Zoetendal, E.G., Kleerebezem, M. \& de Vos, W.M. Microbial communities in the human small intestine: coupling diversity to metagenomics. Future Microbiol. 2, 285-295 (2007).

3. Zoetendal, E.G., Vaughan, E.E. \& de Vos, W.M. A microbial world within us. Mol. Microbiol. 59, 1639-1650 (2006).

4. Morelli, L. Postnatal development of intestinal microflora as influenced by infant nutrition. J. Nutr. 138, 1791S-1795S (2008).

5. Round, J.L. \& Mazmanian, S.K. The gut microbiota shapes intestinal immune responses during health and disease. Nat. Rev. Immunol. 9, 313-323 (2009).

6. Mazmanian, S.K. \& Kasper, D.L. The love-hate relationship between bacterial polysaccharides and the host immune system. Nat. Rev. Immunol. 6, 849-858 (2006).

7. Mazmanian, S.K., Liu, C.H., Tzianabos, A.O. \& Kasper, D.L. An immunomodulatory molecule of symbiotic bacteria directs maturation of the host immune system. Cell 122, 107-118 (2005).

8. Wang, Q. et al. A bacterial carbohydrate links innate and adaptive responses through Toll-like receptor 2. J. Exp. Med. 203, 2853-2863 (2006).

9. Mazmanian, S.K., Round, J.L. \& Kasper, D.L. A microbial symbiosis factor prevents intestinal inflammatory disease. Nature 453, 620-625 (2008).

10. Ruiz-Perez, B. et al. Modulation of surgical fibrosis by microbial zwitterionic polysaccharides. Proc. Natl. Acad. Sci. USA 102, 16753-16758 (2005).

11. Koloski, N.A., Bret, L. \& Radford-Smith, G. Hygiene hypothesis in inflammatory bowel disease: a critical review of the literature. World J. Gastroenterol. 14, 165-173 (2008).

12. Vael, C., Nelen, V., Verhulst, S.L., Goossens, H. \& Desager, K.N. Early intestinal Bacteroides fragilis colonisation and development of asthma BMC Pulm. Med. 8, 19 (2008).

13. Ochoa-Reparaz, J. et al. Role of gut commensal microflora in the development of experimental autoimmune encephalomyelitis. J. Immunol. 183, 6041-6050 (2009).

14. Coombes, J.L. et al. A functionally specialized population of mucosal CD103+ DCs induces Foxp3+ regulatory T cells via a TGF-beta and retinoic acid-dependent mechanism. J. Exp. Med. 204, 1757-1764 (2007).

15. Coombes, J.L. \& Powrie, F. Dendritic cells in intestinal immune regulation. Nat. Rev. Immunol. 8, 435-446 (2008).

16. Dunne, P.J., Moran, B., Cummins, R.C. \& Mills, K.H. CD11C+CD8alpha+ dendritic cells promote protective immunity to respiratory infection with Bordetella pertussis. J. Immunol. 183, 400-410 (2009).

17. Hao, X., Kim, T.S. \& Braciale, T.J. Differential response of respiratory dendritic cell subsets to influenza virus infection. J. Virol. 82, 4908-4919 (2008).

18. Kim, T.S. \& Braciale, T.J. Respiratory dendritic cell subsets differ in their capacity to support the induction of virus-specific cytotoxic CD8+ T cell responses. PLoS One 4, e4204 (2009). 
19. Yokote, $\mathrm{H}$. et al. NKT cell-dependent amelioration of a mouse model of multiple sclerosis by altering gut flora. Am. J. Pathol. 173, 1714-1723 (2008).

20. Lavasani, S. et al. A novel probiotic mixture exerts a therapeutic effect on experimental autoimmune encephalomyelitis mediated by IL-10 producing regulatory T cells. PLoS One 5, e9009 (2009).

21. Duan, J., Avci, F.Y. \& Kasper, D.L. Microbial carbohydrate depolymerization by antigen-presenting cells: deamination prior to presentation by the MHCIl pathway. Proc. Natl. Acad. Sci. USA 105 5183-5188 (2008)

22. Gonnella, P.A., Waldner, H.P., Kodali, D. \& Weiner, H.L. Induction of low dose oral tolerance in IL-10 deficient mice with experimental autoimmune encephalomyelitis. J. Autoimmun. 23, 193-200 (2004).

23. Zhang, X. et al. IL-10 is involved in the suppression of experimental autoimmune encephalomyelitis by CD25+CD4+ regulatory T cells. Int. Immunol. 16, 249-256 (2004).

24. Bettelli, E. et al. IL-10 is critical in the regulation of autoimmune encephalomyelitis as demonstrated by studies of IL-10- and IL-4-deficien and transgenic mice. J. Immunol. 161, 3299-3306 (1998).

25. Hofstetter, H.H. et al. Therapeutic efficacy of IL-17 neutralization in murine experimental autoimmune encephalomyelitis. Cell. Immunol. 237, 123-130 (2005)

26. Komiyama, Y. et al. IL-17 plays an important role in the development of experimental autoimmune encephalomyelitis. J. Immunol. 177, 566-573 (2006).

27. Sutton, C., Brereton, C., Keogh, B., Mills, K.H. \& Lavelle, E.C. A crucial role for interleukin (IL)-1 in the induction of IL-17-producing T cells that mediate autoimmune encephalomyelitis. J. Exp. Med. 203, 1685-1691 (2006).

28. Billiau, A. et al. Enhancement of experimental allergic encephalomyelitis in mice by antibodies against IFN-gamma. J. Immunol. 140, 1506-1510 (1988).

29. Duong, T.T., Finkelman, F.D., Singh, B. \& Strejan, G.H. Effect of antiinterferon-gamma monoclonal antibody treatment on the development of experimental allergic encephalomyelitis in resistant mouse strains. J. Neuroimmunol. 53, 101-107 (1994).

30. Ferber, I.A. et al. Mice with a disrupted IFN-gamma gene are susceptible to the induction of experimental autoimmune encephalomyelitis (EAE). J. Immunol. 156, 5-7 (1996).

31. Chu, C.Q., Wittmer, S. \& Dalton, D.K. Failure to suppress the expansion of the activated CD4 T cell population in interferon gamma-deficient mice leads to exacerbation of experimental autoimmune encephalomyelitis. J. Exp. Med. 192, 123-128 (2000).

32. Willenborg, D.O., Fordham, S., Bernard, C.C., Cowden, W.B. \& Ramshaw, I.A. IFN-gamma plays a critical down-regulatory role in the induction and effector phase of myelin oligodendrocyte glycoproteininduced autoimmune encephalomyelitis. J. Immunol. 157, 3223-3227 (1996).

33. Karpus, W.J. \& Ransohoff, R.M. Chemokine regulation of experimental autoimmune encephalomyelitis: temporal and spatial expression patterns govern disease pathogenesis. J. Immunol. 161, 2667-2671 (1998).

34. Harrington, L.E. et al. Interleukin 17-producing CD4+ effector T cells develop via a lineage distinct from the Thelper type 1 and 2 lineages. Nat. Immunol. 6, 1123-1132 (2005).

35. Park, $\mathrm{H}$. et al. A distinct lineage of CD4 T cells regulates tissue inflammation by producing interleukin 17. Nat. Immunol. 6, 1133-1141 (2005).

36. Voorthuis, J.A. et al. Suppression of experimental allergic encephalomyelitis by intraventricular administration of interferon-gamma in Lewis rats. Clin. Exp. Immunol. 81, 183-188 (1990).

37. Espejo, C. et al. Treatment with anti-interferon-gamma monoclonal antibodies modifies experimental autoimmune encephalomyelitis in interferon-gamma receptor knockout mice. Exp. Neurol. 172, 460-468 (2001).

38. Ochoa-Reparaz, J. et al. Regulatory T cell vaccination without autoantigen protects against experimental autoimmune encephalomyelitis. J. Immunol. 178, 1791-1799 (2007). 